\title{
A Santíssima Trindade do Mosteiro de Itaici
}

\author{
Christiane Meier'
}

DOI 10.20396/eha.vil4.3435

Introdução

O ser humano é iconotrópico, isto é, tem uma necessidade contumaz por imagens, sejam literárias ou plásticas, para construir sua identidade, seu mundo e sua cultura. A sociedade ocidental contemporânea, por sua vez, é iconólatra; é possível notar este fenômeno por meio da quantidade de imagens divulgadas diariamente. Recordemos que a palavra imagem é derivada do latim imago e tem o sentido de semelhança, representação, retrato. Segundo o Dicionário Houaiss, ela pode ter várias acepções, mas será utilizada neste artigo com o significado de "objeto por meios artísticos (imagem desenhada, gravada, pintada)", portanto, bidimensional.

Com a abundância de vídeos, fotografias, grafites, gravuras e pinturas entre outros, pouca atenção pode ser dada a seu conteúdo, sendo necessário tempo e observação para compreendê-los com profundidade. Há os que carecem de um olhar atencioso, que não se deixam apreciar com facilidade; necessitam de tempo para a maturação do pensamento, por meio de atenta observação, análise e comparação.

A presente comunicação tem como objetivo apresentar uma análise da Santíssima Trindade de Cláudio Pastro, no Mosteiro de Itaici, e sua recepção na sociedade contemporânea; em seguida, averiguaremos como a obra dialoga com um protótipo do século XV.

Notamos como o afresco de Pastro carrega, em seu cerne, uma visão de mundo, de tempo e sociedade. Importante ler este ponto de vista, esta Weltanschauung, dado que toda imagem deseja transmitir uma mensagem e não se restringir apenas a seu aspecto estético. Lembramos que Pastro foi um pintor sacro que buscou inspiração na arte cristã da baixa Idade Média; declarava-se um artista que se deixava influenciar pelas tipologias da arte que servem à liturgia e à Igreja. Dizia ser

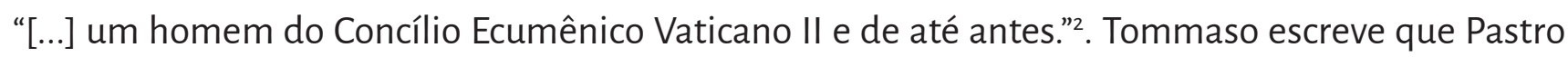

\footnotetext{
1 Mestre em Ciências Humanas pela UNISA, especialista em História da Arte pela FAAP, graduada em Tradução pela Universidade Johannes Gutenberg de Mogúncia, Alemanha. Pesquisadora do Laboratório de Política, Comportamento e Mídia - LABÔ-PUC/SP

2 Pastro, 2013, p. 6
} 
"ao falar de sua espiritualidade, citava Fra Angélico quando este dizia que, para se fazer as coisas de Cristo, é preciso pertencer a Cristo."3. O próprio artista indica, desta forma, sua fé, seu arco temporal e artístico, bem como o acervo iconofotológico ${ }^{4}$ que emprega nas suas imagens.

Observaremos assim até que ponto ele seguiu os cânones bizantinos da arte sacra e ficaremos no encalço de uma resposta à indagação, se, no século XXI, ainda faz sentido trilhar uma tradição que remonta à Protoigreja. Buscaremos entender se Pastro, de fato, ousou uma solução moderna e inovadora, sem abandonar, contudo, os preceitos da arte sacra cristã latina e oriental.

A Santíssima Trindade de Itaici

O mosteiro jesuítico de Itaici (figura 01), localizado no município de Indaiatuba, no interior de São Paulo, é também conhecido por Vila Kostka, uma homenagem ao santo padroeiro dos noviços da Cia. de Jesus, Estanislau Kostka. Em 1950, no local de uma antiga fazenda, iniciou-se a construção atual, inspirada na arquitetura da Universidade Federal Rural do Rio de Janeiro. O edifício, com várias alas de dois andares, abriga a capela da Santíssima Trindade, no andar superior de uma das alas.

Ao entrar na capela, o visitante abarca, de uma só vez, a composição do mural que estará à sua esquerda. Os três anjos de tamanho maior que o natural prendem a atenção; contudo, talvez o observador não esteja, de fato, enxergando a sua totalidade. O anjo que o encara parece convidá-lo a olhar com calma e em detalhe, pois, quiçá, haja ali mais do que três seres celestiais sentados à mesa.

A obra foi realizada em 1990 e que toma toda a parede de fundo do altar (figura 02). A composição é estilizada e carregada de simbologia como a arte sacra ou litúrgica deve ser. O mural é calcado em passagem do Antigo Testamento e na tipologia de um ícone produzido na Rússia do século XV: três anjos sentados à mesa com um recipiente ao centro. Diferentemente do iconógrafo russo, que pintou sobre madeira, Pastro retoma a arte cristã da Protoigreja e concebe sua obra em afresco, utilizando, contudo, um traço contemporâneo.

O tema encontra-se no Gênesis e descreve a ocasião em que Abraão recebe em seu acampamento, em Mambré, três seres celestiais, lava-lhes os pés e os alimenta. Nas Escrituras lemos: 


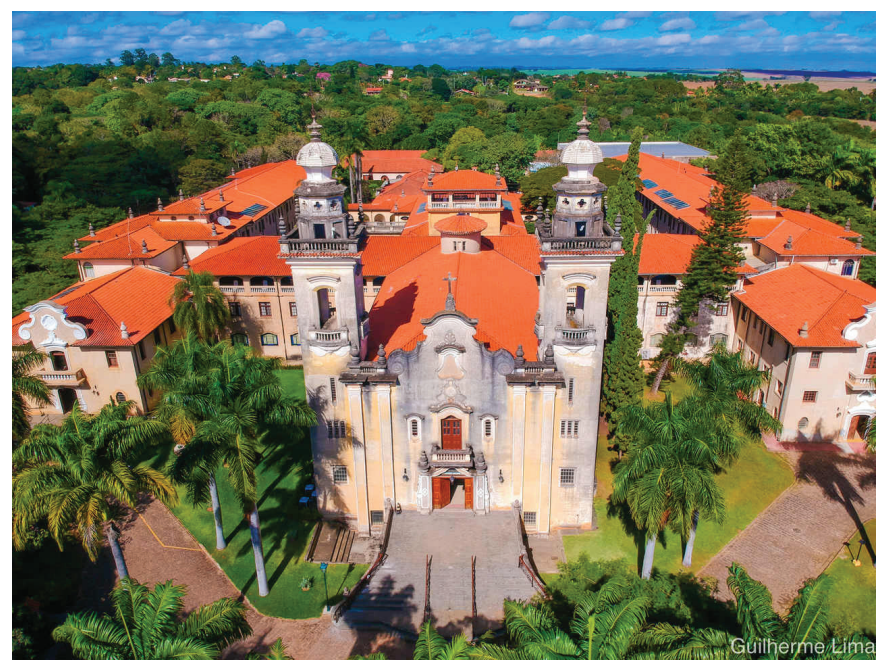

\section{[Figura 01]}

Mosteiro de Itaici, Indaiatuba

https://www.vilamanresa.com.br/img/mostei-

ro/vila-manresa-mosteiro-itaicio3.jpg

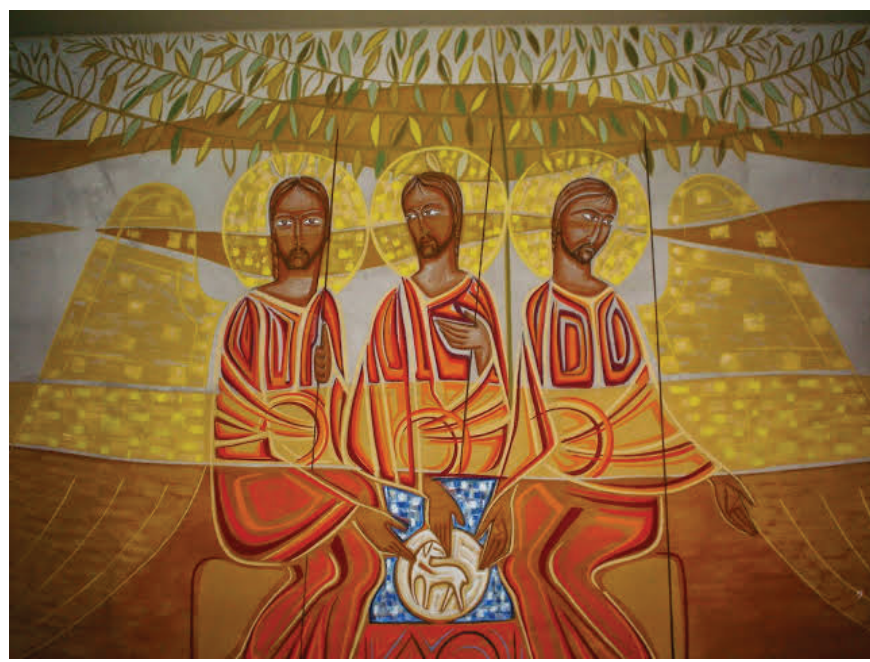

[Figura 02] Cláudio Pastro, Santíssima Trindade, capela da SS Trindade, Mosteiro de Itaici

https://www.tripadvisor.com.br/LocationPhotoDirectLink-g303613d7235535-i266302719-Mosteiro_de_Itaici-Indaiatuba_State_of_Sao_Paulo.html

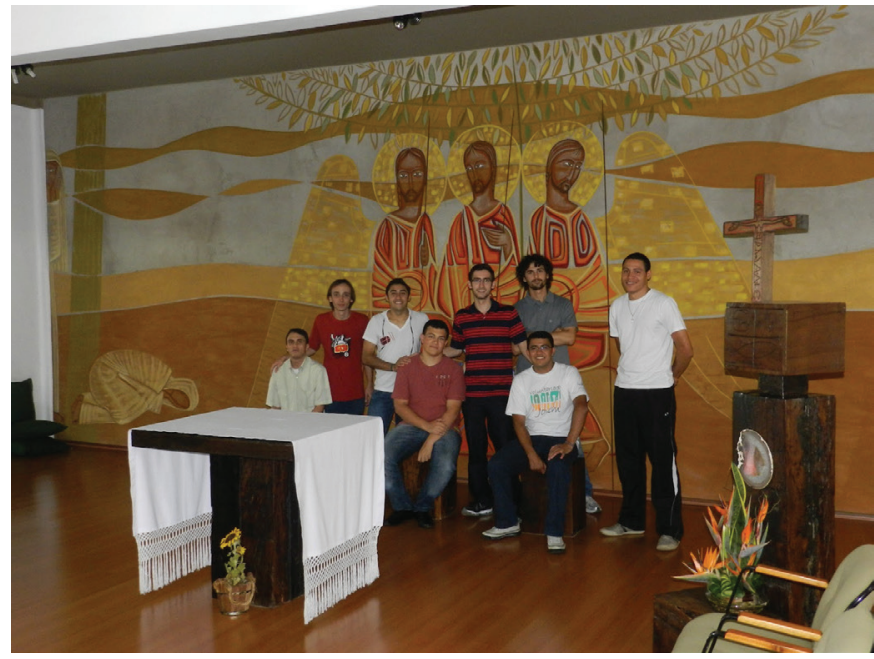

\section{[Figura 04]}

Igreja Viva, grupo diante do afresco da Santíssima Trindade, Capela da SS Trindade, Mosteiro de Itaici https://www.tripadvisor.com.br/Mosteiro_de_ Itaici-Indaiatuba_State_of_Sao_Paulo.html 
lahweh the apareceu no Carvalho de Mambré [...]. Tendo levantado os olhos, eis que viu três homens em pé, perto dele; logo que os viu, correu da entrada da tenda ao seu encontro e se prostrou por terra. E disse: 'Meu Senhor, eu te peço, se encontrei graça aos teus olhos, não passe junto de teu servo sem te deteres.' (Gn 18, 1-3)

O Patriarca dirige-se a eles no singular; chama-os de 'Senhor', apesar de serem três. Este fato levou a interpretações relacionando os anjos à Trindade Santa, Pai, Filho e Espírito Santo, à manifestação do Deus trino e uno no mundo sensorial. Sua tipologia ficou conhecida como a Santíssima Trindade, na Igreja russa, e a Hospitalidade ou a Xenofobia de Abraão, na Igreja grega, tornandose símbolo do amor cristão, da caridade para com estrangeiros e viajantes.

Tal formação de matriz iconográfica a partir de uma imagem logótica é descrita por Panofsky: "Observará [o espectador] a interligação entre as influências das fontes literárias e os efeitos de dependência mútua das tradições representacionais, a fim de estabelecer a história das fórmulas iconográficas ou 'tipos'." . Burckhardt, por sua vez, afirma que, na perspectiva cristã, "as realidades eternas aparecem sob a forma de eventos históricos" ${ }^{\prime 6}$ e assim passíveis de serem reproduzidos pictoricamente.

A imagem bíblica do encontro em Mambré entra para o repertório dos artistas plásticos, tornando-se uma iconografia corrente, tanto na Igreja latina como na ortodoxa, desde as catacumbas romanas até o século XXI. Apesar de esta representação iconográfica ser conhecida desde o século V, é no século XV, na Rússia, que se consagra como protótipo largamente usado até o presente: a Santíssima Trindade de Rublev (figura 03).

Esse modelo evoca o diálogo entre as pessoas da Trindade que estão a debater a estratégia de salvação da humanidade. As Escrituras Sagradas, contudo, não narram qualquer plano de redenção; é na Patrística, em Ambrósio e Agostinho, e em místicos medievais que os artistas buscarão estas imagens logóticas, para transpô-las em iconográficas, segundo Boespflug (2013). Segue o autor informando que Deus tem planos e os debates resultarão na estratégia das intervenções neste mundo: o Espírito Santo será enviado para dar vida e o Filho virá para vencer o mal e a morte.

Mas, ao contrário do iconógrafo russo, que pintou sobre madeira, em Itaici, o artista retoma a arte cristã medieval e concebe sua obra em forma de afresco, pintura sobre parede úmida, utilizando um traço contemporâneo e simbólico que dialoga com a arte da Protoigreja cristã. Segundo Sartorelli, Pastro "dentro de sua análise de sacro e religioso na arte, [...] valoriza a arte e a arquitetura

\footnotetext{
5 Panofsky, 2014, p. 37

6 Burckhardt, 2004, p. 120
} 
do primeiro milênio do cristianismo." 7 .

O mural de cerca de $20 \mathrm{~m}^{2}$, tem dimensões humanas que aproximam o sagrado do observador. Diferentemente da Idade Média, quando a sociedade era cristocêntrica e antropoperiférica, o pintor subverte a lógica e a atualiza, procedendo ao aggiornamento recomendado pelo Concílio Vaticano II: os artistas deveriam atualizar a arte sacra paleocristã. Seguindo essa orientação, ele concebe sua obra de forma contemporânea, empregando a escala humana, mas o faz a um só tempo cristocêntrica - dado que o Deus trino e uno é o centro visual - e antropocêntrica, já que tem as dimensões do homem.

O ícone de Rublev, por sua vez, é, sem dúvida, antropoperiférico, dada sua escala reduzida $(1,42 \times 1,14 \mathrm{~m})$ que afasta o sagrado do mundo sensível, tornando a obra uma janela para o transcendental. O iconógrafo acentua o caráter celestial dos seres representados ao empregar cores claras e diáfanas. Em Pastro, as cores terrosas são indicativas do Emanuel, 'Deus conosco', do Verbo Encarnado que viveu entre nós, da Trindade Santa neste mundo. Este sentimento reverbera no visitante, como pode ser constatado na selfie de jovens (figura 04); o grupo e a Trindade parecem formar um só conjunto, uma comunidade. A legenda da foto explica tratar-se da "Igreja viva", como se os três anjos pertencessem ao grupo fotografado.

Faixas horizontais perpassam todo o mural, lembrando as dunas do deserto onde Abraão descansava, mas, igualmente, remetendo a pautas musicais. Não somente a linha na altura dos olhos dos anjos pode vir a formar uma melodia em nosso interior, mas a pintura toda lembra uma partitura, evoca música. Contudo, as pautas são formadas por cinco linhas, o pentagrama, e aqui contamos sete, número considerado místico, espiritual. Sete é a soma do número três (a perfeição, a própria Trindade Santa) com o quatro (a Terra, já que quatro são os pontos cardeais, as estações do ano, p.ex.). Deus criou o mundo em sete dias, portanto, sete são os dias da semana, as esferas celestes, as notas musicais, os arcanjos, as hierarquias dos anjos, etc. Sete é a síntese da combinação do sagrado (três) com o terreno (quatro), Deus no mundo, a Santíssima Trindade na capela de mesmo nome, evocando a presença do divino ali.

Segundo descrição de Pe. Rámon, "o mural revela traços ondulatórios, alongando, desse modo, o lugar quadrado da capela."8. O aspecto mencionado, as linhas que alongam a capela, remete-nos ao preceito medieval de que a arte sacra cristã, em especial o mosaico e o afresco, deve acompanhar a arquitetura. Nesse sentido, é possível observar a utilização das linhas para 'alongar' 
a parede e dar diversidade ao olhar, chamando a atenção para o mural.

Observado o ícone de Rublev, nota-se que ele apresenta três seres celestiais sentados à mesa com um cálice ao centro; sabemos tratar-se de anjos peregrinos, pois cada um porta um cajado em sua mão. Peregrinos que, segundo o Gênesis, são acolhidos por Abraão. Na obra de Rublev, não vemos Abraão, mas sabemos de sua participação na cena assim como a de Sara, sua esposa, pois, ao ouvir o prenúncio de que teria um filho, riu (Gn 18). Na composição de Pastro há, igualmente, três anjos peregrinos portando seus cajados e, ao contrário da composição russa, Abraão, em profunda prostração, e Sara, semioculta e ouvindo a conversa, estão também presentes.

Ao examinar as faces dos anjos, notamos que eles têm o mesmo rosto, apesar de não terem uma fisionomia de uma determinada pessoa; ao contrário, os semblantes são estilizados, representando qualquer e todos os homens. São magros, longilíneos e de tez morena; portam barba aparada e cabelo longo, ambos castanhos. As feições são de um adulto por volta dos trinta e cinco anos de idade, com olhar sério, boca pequena e nariz afilado; os ol hos escuros são muito grandes. Vemos que são idênticos, só variando suas posturas: dois estão com os rostos levemente virados, em três quartos (um para a esquerda e outro para a direita) e um encara o observador de frente.

Encontramo-nos diante da imagem triplicada de Cristo, representado na sua forma consagrada, da Santa Face. Pastro deve ter optado por esta representação, já que Jesus afirmara ser a imagem do Pai e, por consequência, da Trindade Santa. Assim, diferentemente de Rublev, que pinta sua Trindade com rosto de anjos, Pastro pinta três vezes o mesmo rosto do Redentor.

As roupas são estilizadas e idênticas: temos a impressão de ver túnica e manto que lembram as utilizadas no Império romano. Sua composição é gráfica, arranjada com linhas, traços, semicírculos e superfícies em amarelo, laranja, branco, ocre e marrom. No geral, a paleta do artista é enxuta, predominando os tons terrosos.

Observamos somente duas grandes asas amarelas com pontos cintilantes, mas podemos intuir que cada anjo tem um par. As duas visíveis emolduram as três pessoas, reafirmando a sua natureza una e trina, triuna, Deus-Pai, Deus-Filho e Deus-Espírito Santo. Por trás de suas cabeças, veem-se auréolas individuais igualmente amarelas, com tufos da mesma cor, como que cintilando, dando a impressão de luz bruxuleante. Segundo o Credo de Nicéia, "Jesus é Luz de Luz", e, assim, pode-se inferir que Deus é luz; lembrando ainda que Javé-Deus, no Antigo Testamento, é a sarça ardente que não se consome (Ex1) e ainda a coluna de fogo que guia Moisés e seu povo no deserto (Ex 13, 21-22). Esses pontos em amarelo se repetem nas asas, remetendo à promessa feita pelos anjos de que o anfitrião teria muitos descendentes com sua esposa Sara: "Olha para o céu e conte as estrelas, 


\section{[...] assim será tua posteridade." (Gn 15, 5).}

Os três portam bastão longo e fino e estão sentados muito próximos uns dos outros, sobre cubos iguais aos bancos do altar da capela. À sua frente, vemos uma superfície que se parece com uma pequena mesa, concebida sem perspectiva, da mesma forma que em pinturas da Idade Média. Sobre esta, um objeto redondo, um medalhão, um prato talvez, com um animal estilizado, um cordeiro, que parece cair para fora da pintura. Temos a impressão que o cordeiro está vivo e não imolado, como seria de se esperar de um prato servido sobre a mesa. O tampo, um mosaico em azul e branco, atrai o olhar do visitante, pois sobressai dos tons quentes e ressalta o recipiente com o animal, fazendo que pareça flutuar, lembrando um holograma. Abaixo, veem-se a primeira e a última letra do alfabeto grego, alfa e ômega, emolduradas pelos pés descalços dos dois personagens externos.

A pessoa da esquerda de quem olha o afresco está de frente, encarando o fiel e o convida a olhar sua mão direita apontando para o centro, para sua estratégia de salvação: o cordeiro que virá ao mundo e triunfará sobre o pecado e a morte. Trata-se de Deus-Pai, com três dedos indicando o seu plano e reafirmando assim a comunidade em uma só pessoa, Deus uno e trino. Ao centro, temse o Filho, mirando o Pai e indicando com a mão o seu papel: a de cordeiro que vencerá o mal e a morte. À direita, o visitante identifica aquele que já está pronto para iniciar sua missão, a de vir ao mundo e dar vida: o Espírito Santo. Sua mão, com a palma virada para cima, está aberta, aceitando seu papel; seu olhar é em direção para onde deve seguir. Ele já não porta mais o seu cajado, pois o passou aos bispos que devem conduzir a Igreja.

A obra não tem luminosidade própria, não encontramos um ponto iluminador, apesar de as asas e as auréolas cintilarem. Ela segue o cânone bizantino dos ícones, onde a luz não é natural, mas espiritual, difusa, que não gera sombras e tampouco ressalta partes do trabalho; é a mesma luminosidade observada em Rublev.

Outro ponto de contato com o iconógrafo russo é a perspectiva. Pastro não emprega a perspectiva linear, aquela que imita o mundo sensível. Ele se utiliza da perspectiva inversa, que não busca a mimese, mas está centrada no observador; seu ponto de fuga está no olhar de quem vê o ícone. Pelas dimensões da obra em Itaici, a perspectiva inversa coloca o observador junto à Santíssima Trindade e a capela passa a ser a tenda de Abraão, com seus dois postes representados no afresco e outros dois, imaginariamente, atrás do observador. Pintando em tamanho maior que o natural e utilizando o ponto de fuga no espectador, Pastro envolve-o na cena à sua frente e traz o divino para a dimensão do humano. 


\section{Considerações finais}

Constatamos que a obra de Pastro necessita de tempo para que o observador possa analisar todos os seus aspectos, buscar em sua memória imagens para comparação e abarcar, desta forma, seu conteúdo e sua mensagem. Goethe afirmara que "a obra de arte [...] longe de imitar uma natureza visível, torna visível um mundo ainda desconhecido." ${ }^{\prime \prime}$, tendo sido este o nosso ponto de partida: o descortinar de um conteúdo não aparente de imediato, uma imagem que, mesmo sendo abarcada a uma só vez, não é compreendida de pronto.

Vimos que, apesar de o artista ter utilizado tipologias das Igrejas latina e ortodoxa e se pautado no cânone artístico da Protoigreja, ele inovou e trouxe solução transformadora para seu mural, seja na dimensão, no traço contemporâneo ou na forma que posicionou o visitante junto ao sagrado. Confirmamos que a obra, quando analisada em detalhe e sua mensagem apreendida na totalidade, denota o diálogo e a música que emana do conjunto. Contudo, ela não agita o espectador, mas o leva à introspecção, como no depoimento de quem muitas vezes esteve ali a contemplar e meditar: "[...] o artista não fechou o horizonte do que contemplamos, deixando espaços sem pintar. Esses vãos induzem-nos a superar o que meramente vemos. As ondulações das dunas ampliam o nosso espaço de visão exterior e interior."10.

Pastro, por sua vez, afirma que "outra questão para mim é realizar uma obra que seja continuidade da arte sacra no 'rio de água viva' que provém do Cordeiro e perpassa toda a história da Igreja e da humanidade." E, dentro deste espírito ele cria seu afresco em Itaici, trazendo o sagrado para o mundo contemporâneo, aproximando o visitante e o fiel do Deus trino e uno, concedendoIhe, porém, de forma contemporânea, espaço para seus próprios pensamentos e sentimentos. 


\section{Referências bibliográficas}

Bíblia de Jerusalém, Paulus, 2016

BOESPFLUG, François. Der Gott der Maler und Bildhauer - die Inkarnation des Unsichtbaren, Verlag Herder, Freiburg im Breisgau: 2013

BRANDÃO, Jack (org.). Apontamentos imagético-interdisciplinares: as artes iconológica, pictográfica, fotográfica e literária, Editora Lumen et Virtus, Embu-Guaçu: 2014

BURCKHARDT, Titus. A arte sagrada no Oriente e no Ocidente: princípios e métodos, Attar Editorial, São Paulo: 2004 LACOSTE, Jean. A Filosofia da Arte, Jorge Zahar Editor, Rio de Janeiro: 1986

PANOFSKY, Erwin. Significado nas artes visuais, Editora Perspectiva, São Paulo: 2014

PASTRO, Claudio. A Arte no Cristianismo, Paulus, São Paulo: 2010

Imagens do invisível na arte sacra de Cláudio Pastro, Edições Loyola, São Paulo: 2013

SARTORIELLI, César Augusto. O espaço sagrado e religioso na obra de Claudio Pastro, Almeida Casa Editorial, São Paulo: 2013

TOMMASO, Wilma. A Contrarreforma e a arte colonial no Brasil, sem data, em https://www.academia.edu, acessado em 30/09/2018

O Cristo Pantocrator - da origem às igrejas no Brasil, na obra de Cláudio Pastro, Paulus, São Paulo: 2017

http://www.terraboa.blog.br/2017/06/capela-da-ss-trindade-em-itaici, acessado em 25/06/2019 